\title{
Utilization of oral health services by mothers of preschool children in Jos North Local Government Area, Plateau State, Nigeria
}

\author{
Adeleke 0. A, Danfillo I.S \\ Regional Centre for Oral Health Research and Training initiatives (RCORTI) for Africa, Jos, Nigeria. \\ Correspondence to: $\mathrm{Dr}$. 0. A. Adeleke, Regional Centre for Oral Health Research and Training initiatives \\ (RCORTI) for Africa, (In collaboration with World Health Organization), No 3 CBN Road, P.M.B. 2067, Jos. Plateau State. Nigeria. \\ E-mail: adeleke10@yahoo.co.uk.
}

SUMMARY

Objective: To determine oral health services utilization by mothers of pre school children in Jos North Local Government Area, Plateau State, Nigeria

Design: Cross-sectional study

Setting. Four Primary Health Care (PHC) Clinics in Jos

North Local Government Area

Participants: 200 mothers of pre school children

Materials and Methods: Mothers of pre school children were proportionately sampled in four randomly selected clinics. Structured questionnaires were administered to them in order to obtain information on the utilization of oral health services, their reasons for visitation and non visitation

Results Twelye and half percent $(12.5 \%)$ of the mothers reported ta have visited the dentist before while only $4.5 \%$ of the children of mother's surveyed had been taken to the dentist at least once. Literate mothers visited the dentist more compared to the illiterate mothers. All the illiterate mothers visited the dentist when there was a dental problem. All the mothers who were aged less than 20 years and their children had never visited a dentist. Cumulatively, $94 \%$ of the mothers gave lack of perceived need as their reason for non utilization of dental services.

Conclusion: The study showed that majority of mothers based their dental visits on presence of a dental problem and perceived need. Further studies are needed on oral health services utilization to better understand the role of socio-cultural barriers.

\section{Introduction}

Utilization of health services in dentistry refers to the number of individuals who make use of dental sevices. The most common measure of utilization is annual number of dental visits per person. ${ }^{2}$ This information will help in the planning and implementation of oral health services in a community. There are many factors reported to directly and indirectly influence a person's utilization of oral health services; such as ill health related factors, service related factors, socio- demographic factors and attitudinal factors. ${ }^{2}$ Oral health utilization behaviour also influences an individual's oral health status.

Many studies conducted in industrialized and middle-income developing countries show that, as a result of limited access to dental care ${ }^{3,4,57}$ low socio economic status groups have lower utilization rates of oral health service. ${ }^{8,9,10}$.

Individuals of low socio economic status (SES) have many financial, material and social disadvantages, all of which may adversely affect oral health. Many of these individuals suffer through a vicious cycle of poverty, constantly encountering problems with education, housing and work. Furthermore, low SES individuals often have fewer resources available to secure nutritious foods, adequate health care and other elements necessary for maintaining a satisfactory level of health and quality of life. Under these circumstances, prevention of oral diseases and oral health maintenance often become a lower priority. 11

On matters of child dental health and attendance at the dental clinic, the mother's role has been found to be more important than that of the father. ${ }^{12}$ Mothers' dental attendance pattern is known to be an important indicator of dental attendance and health in young children. ${ }^{13}$ Mothers who had visited the dentist recently were likely to have registered their pre-school children with the dentist and adult dental attendees were more likely to have been taken to the dentist frequently during childhood. ${ }^{14}$ This preliminary study was carried out to determine the level of utilization and reason for non-utilization of oral health service by mothers of pre school children in Jos, Plateau State of Nigeria.

\section{Materials and methods}

The study was conducted in Jos North Local Government Area (LGA) of Plateau State which has a projected 2003 population of 526, 236 from the 1991 population It is bounded in the North East by Bauchi State, North - West by Bassa LGA and in the South by Jos South LGA. It has one administrative district, which is Gwong district and four health districts, which are Nassarawa Gwong, Naraguta, Jos Township and Tudun-Wada districts. It has fourteen wards and twenty village areas.

The LGA is mainly inhabited by traders, civil servants and farmers. Jos North LGA is cosmopolitan. Jos is the capital of city of Plateau State and is within this LGA. Also located in the LGA are the Jos University Teaching Hospital and the University of Jos. It also has a state specialist hospital, twenty Primary Health Care centres, two mission hospitals and over 100 privately owned clinics.

Township PHC clinic, one of those selected was established in 1920 and it caters for the health care needs of members of the LGA in the middle to lower social strata. The remaining three PHC centres were Tudun Wada, Nassarawa and Naraguta - all of which were established in the 1980s and cater for the lower social strata. Services offered at all the PHC Centres include immunization, antenatal care, deliveries, postnatal and family planning activities.

This is a cross-sectional study involving mothers attending Primary Health Care (PHC) clinics in Jos North Local Government Area. Four (4) of these clinies were randomly selected from which mothers attending on clinic days were selected. (130 was the minimum sample size obtained by using a prevalence level (P) of $90.7 \%$ being the percentage of women who were brushing their children's' teeth from a study done at Ibadan by Aderinokun, Arowojolu\& Arowojolu ${ }^{16}$. Precision level (d) was 5\%).

Data collection was by the interviewer-administered questionnaire. The investigator at each of the four PHC Clinics surveyed 
administered the questionnaires. The interview sought information on the mothers' socio demographic characteristics, child and mothers' dental visits, and reasons for non-visitation. The questionnaires used were pilot tested and modified as necessary until a sensitive survey instrument was developed.

Approval for the study conducted in Jos North LGA was obtained from the Chairman of the LGA through the office of the Coordinator, Primary Health Care Programme. Mothers' consents were obtained in writing.

All the completed questionnaires were analyzed using SPSS 9. Data from pre-coded questionnaires were entered into the computer. Chi square test was used to investigate the association between mother's age, education, and utilization of oral health service.

\section{Results}

A total of 200 mothers attending four Primary Health care Clinics (PHC) were included in the study. Sixty-eight (34\%) of the mothers that were interviewed were aged 25 - 29 years, $24.5 \%$ were aged $20-24$ years, $20 \%$ were aged $30-34$ years, $18.5 \%$ were more than or aged 35 years, while only $6(3 \%)$ were below the age of twenty years. The mean age was $28 \pm 6$ years. (Table1). Most of the mothers who were interviewed were literate $(60.5 \%)$ with $38.5 \%, 17.5 \%$ and $4.5 \%$ having primary, secondary and tertiary education respectively. Seventy nine $(39.5 \%)$ of the mothers had no formal education.

Table 1: Distribution of surveyed mothers by age, educational status, occupation and marital status.

\begin{tabular}{|c|c|c|c|}
\hline Characteristic & & Frequency & $\%$ \\
\hline \multirow[t]{6}{*}{ Age in years } & $<20$ & 6 & 3 \\
\hline & $20-24$ & 49 & 24.5 \\
\hline & $25-29$ & 68 & 34 \\
\hline & $30-34$ & 40 & 20 \\
\hline & $>35$ & 37 & 18.5 \\
\hline & Total & 200 & 100 \\
\hline \multirow{5}{*}{$\begin{array}{l}\text { Educational } \\
\text { status }\end{array}$} & Illiterate & 79 & 39.5 \\
\hline & Primary & 77 & 38.5 \\
\hline & Secondary & 35 & 17.5 \\
\hline & Tertiary & 9 & 4.5 \\
\hline & Total & 200 & 100 \\
\hline \multirow{7}{*}{$\begin{array}{l}\text { Mother's } \\
\text { occupation }\end{array}$} & Houscwife & 94 & 47 \\
\hline & Trading & 51 & 25.5 \\
\hline & Civil servant & 12 & 6 \\
\hline & Skilled & 29 & 14.5 \\
\hline & Unskilled & 6 & 3 \\
\hline & Others & 8 & 4 \\
\hline & Total & 200 & 100 \\
\hline \multirow[t]{5}{*}{ Marital status } & Single & 5 & 2.5 \\
\hline & Married & 191 & 95.5 \\
\hline & Widowed & 3 & 1.5 \\
\hline & Separated & 1 & 0.5 \\
\hline & Total & 200 & 100 \\
\hline
\end{tabular}

As regards dental visits, $25(12.5 \%)$ of the study sample reported to have visited a dentist before, out of which 17 were literate while 8 were illiterate. Only $4.5 \%$ reported to have taken their children for dental visits.
Table 2: Dental visits by mothers' educational status

\begin{tabular}{|c|c|c|c|c|c|}
\hline \multirow[t]{3}{*}{ Dental visit } & & \multicolumn{4}{|c|}{ Educational status } \\
\hline & Illiterate & Literate & Total & $\mathrm{X} 2$ & $\mathrm{p}$-Value \\
\hline & $\mathrm{N}(\%)$ & $N(\%)$ & $N(\%)$ & & \\
\hline $\begin{array}{l}\text { 1. Mothers' } \\
\text { visit }\end{array}$ & & & & & \\
\hline (i) Yes & $8(10.1)$ & $17(14.0)$ & $25(12.5)$ & 0.673 & 0.412 \\
\hline (ii) $\mathrm{No}_{0}$ & $71(89.9)$ & $104(86.0)$ & $175(87.5)$ & & \\
\hline 2. Child's visit. & & & & & \\
\hline (i) Yes & $3(3.8)$ & $6(5.0)$ & $9(4.5)$ & 0.150 & 0.699 \\
\hline (ii) $\mathrm{No}$ & $76(96.2)$ & $115(95.0)$ & $191(95.5)$ & & \\
\hline $\begin{array}{l}\text { 3. Frequency } \\
\text { of mothers' } \\
\text { visit }\end{array}$ & & & & & \\
\hline $\begin{array}{l}\text { (i) Twice a } \\
\text { year. }\end{array}$ & - & $1(5.9)$ & $I(4.0)$ & 1.604 & 0.448 \\
\hline $\begin{array}{l}\text { (ii) Once } \\
\text { a year. }\end{array}$ & - & $2(11.8)$ & $2(8.0)$ & & \\
\hline $\begin{array}{l}\text { (iii) When } \\
\text { there is } \\
\text { a problem }\end{array}$ & $8(100)$ & $14(82.4)$ & $22(88)$ & & \\
\hline $\begin{array}{l}\text { 4. Reasons } \\
\text { for }\end{array}$ & & & & & \\
\hline $\begin{array}{l}\text { non- } \\
\text { visitation. }\end{array}$ & & & & & \\
\hline (i) Distance. & & $2(1.9)$ & $2(1.1)$ & & \\
\hline $\begin{array}{l}\text { (ii) Fcar of } \\
\text { dental } \\
\text { treatment. }\end{array}$ & $1(1.4)$ & $2(1.9)$ & $3(1.7)$ & & \\
\hline $\begin{array}{l}\text { (iii) Never } \\
\text { had a } \\
\text { dental }\end{array}$ & & & & & \\
\hline $\begin{array}{l}\text { problem. } \\
\text { (iv) Traditional }\end{array}$ & $66(93)$ & $99(95.2)$ & $165(94.3)$ & 5.230 & 0.265 \\
\hline $\begin{array}{l}\text { healer. } \\
\text { (v) Went to }\end{array}$ & $2(2.8)$ & $1(1.0)$ & $3(1.7)$ & & \\
\hline a chemist. & $2(2.8)$ & - & $2(1.1)$ & & \\
\hline
\end{tabular}

All the illiterate mothers that reported visiting a dentist, visited when they had a dental problem. All the mothers below the age of 20 years and their children had never visited a dentist.

(Table 3)

Most $(94 \%)$ of the mothers reportedd they did not visit a dentist because they never had a dental problem (Tables $2 \& 3$ ). Other reasons given by the mothers for lack of dental visits were distance, fear of dental treatment, visit to traditional healer and chemist.

\section{Discussion}

Studies on mother's utilization of oral health services are quite important because mothers transmit routines of behaviour conducive to health, which are internalised by the child. In South Manchester, $44 \%$ of mothers and $61 \%$ of children had attended a dentist in the previous 12 months. The mothers' attendance was a good predictor of children's attendance ${ }^{17}$. This is relevant in the present study, as $12.5 \%$ of mothers had visited the dentist while only $4.5 \%$ of their children had visited the dentist.

Studies had reported that among the background variables, age, income, education were the most powerful predictors of use of dental services $;{ }^{18}$ also that family structure, marital status, number of children and age of children were associated with respondents self reported dental attendance pattern. ${ }^{19}$ In this study, more of the illiterate mothers as compared with the literate mothers did not visit the dentist. Furthermore all the mothers less than 20 years and their children did not visit the dentist. This 
may be because difficult socio economic conditions may adversely influence the oral health status of these individuals by indirectly lowering, preventing or postponing their use of appropriate self-care or professional dental service. These conditions include a general inability to pay for dental care ${ }^{20}$ and poor access to dental care. ${ }^{2}$

Individuals of lower education tend not to visit the dentist because their beliefs in their control over their health matters are lower and their perceptions of barriers such as lack of worthiness of the visits, unpleasant past experiences with visits, fear of dental treatment and less positive attitude towards dentists, are higher than the high education groups $\mathrm{s}^{22-24}$.

According to the National Health Survey Interview in the United States, only $68.5 \%$ of women aged 18-64 years reported having a dental visit during the previous 12 months in 1999 , the most commonly cited reason for the non- utilization of dental services among the women is lack of perceived need. ${ }^{25-26}$ The number of mothers who visited the dentist in the studies in the United States was higher when compared to the present study but the reasons cited for non-visitation were similar, as $94 \%$ of the mothers in the present study did not visit the dentist because they reported not to have any dental problem. Lack of oral health knowledge about oral health related matters or the prevention of their own and their children's oral diseases may have accounted for the reason cited for non-visitation as found in other studies. ${ }^{27}$

As regards mothers' dental care, the result from this study is similar to the study in Madagascar ${ }^{29}$ where $18 \%$ of the mothers had visited a dentist while in Baltimore ${ }^{30} 44 \%$ of the women did not have regular dental care and $37 \%$ of Kuwaiti ${ }^{31}$ mothers were seen by a dentist once a year for symptomatic reasons. In the Netherlands ${ }^{32}$ there was lower percentage of women not attending a dentist regularly.

Annual visits to the dentist were reported for $51 \%$ of the mothers in Saudi Arabia ${ }^{33}$ and $20 \%$ of the mothers in the People's Republic of China $^{34}$ had seen the dentist within the past 12 months. In this study, there appears to be a lack of knowledge regarding routine visits to the dentist, as visit to the dentist is considered important only when there is a dental problem. This implies that oral health conditions that would have been detected and treated at the early stages may be seen at advanced stages when they are not treatable.

Only $4.5 \%$ of children of the mothers surveyed had ever visited a dentist. This reveals the paucity of knowledge of the mothers on visiting the dentist. The result obtained in this study is far r low what was obtained in Saudi Arabia ${ }^{33}$ where $45 \%$ of the illdren surveyed had annual visits to the dentist while in Glasgow ${ }^{14} 92 \%$ of the mothers reported that the children visited the dentist for a check-up, only $8 \%$ said that they would wait until the child had suffered from toothache before taking him to see a dentist.

The study highlights that the reason for non utilization of oral health services by majority of the mothers was lack of perceived need. The reason for this low level of utilization may be multi factorial such as lack of oral education as observed in all the clinics visited, and shortage of manpower and facilities. In conclusion, systematic surveys of dental utilization and oral health care outcomes in Plateau State are needed to better understand the role of socio cultural barriers to utilization of oral health services. Research should focus on primary oral health care services. These data, in combination with oral health status and social systems, could form the basis for appropriate interventions.

\section{Acknowledgements}

The investigators acknowledges with thanks the cooperation of the Director, Primary Health Care, Jos North Local Government Area, the District Supervisor and staff of all the clinics surveyed. Our appreciation also goes to all the moth ers who consented to participate in this study. Grateful thanks are extended to Dr. O. O. Taiwo for his contribution to the study, Mr. Phillip Jalo for the statistical analysis and Mr. Steve Job Pam for the data processing. The Regional Centre for Oral Health Research and Training Initiatives (RCORTI) for Africa, Jos, funded the study.

\section{References}

1. Osuji O.O. Utilization of dental services by children at the University College Hospital, Ibadan. Nigeria. Odonto- stomatologie tropicale 1990; 13: 97-99

2. Cohen L.K, Gift H.C. Disease prevention and oral health promotion. Socio-dental sciences in action. FDI London. 1995: 342

3. Grembowski D, Conrad D.A, Milgrom P. Dental care demand among children with dental insurance. Health Serv Res 1987; 21: 755-75

4. Okada L.M, Wan T.T. Impact of community centres and medical aid on the use of health services. Public health Rep 1980; 95: 520-34

5. Yellowitz J.A, Katz R.V, Portnoy R, Smith B. J. The Minnesota dental insurance program for senior citizens: two- year results for the utilization of dental services. J Am Dent Assoc 1982; 104: 453-8

6. Meskin L.H, Dillenberg J, Heft M.W, Katz R.U, Martens L.V. Economic impact of dental service utilization by older adults. $J$. Am Dent Assoc 1990; 120: 665-8

7. Waldman H. B. Increasing use of dental services by the young elderly. $J$ Am Dent Assoc 1990; 20: 665-8

8. Ritchie J, Jacoby A, Bone M. Access to primary health care. I_ondon: HMSO, $\quad 1981$

9. Waldman H.B. Dental insurance coverage and the use of dental services by children. J. Dent Child 1989; 56: 125-8

10. Sheiman A, Maizels J, Cushing A, Holmes J. Dental attendance and dental status. Community Dent Oral Epidemiol 1985; 13: 304-9

11. Locker D. An introduction to behavioural science and dentistry. London. Tavistock / Routledge. 1989.

12. Kinirons M, McCabe M. Familial and maternal factors affecting the dental health and dental attendance of preschool children. Community Dental Health $1995 ; 12: 226-229$

13. Verrips G. H, Kalsbeek H, Eijikman M. A. J. Ethnicity and maternal education as risk indicators for dental caries, and the role of dental behaviour. Community Dent. Oral. Epidemiol 1993; 21: 209 - 14

14. Elizabeth J. Kay, McGuiness Jean. Pregnant Women's Dental Health Knowledge. Dental Health 1990; 29: 3-5

15. National Population Commission - 1991 Population Census of Nigeria, Abuja

16. Aderinokun G.A, Arowojolu M.O, Arowojolu A.O. Perception of child Oral health needs by antenatal clinic attenders in Ibadan, Nigeria. Afr.J. MedSci. 1998; 27(3-4): 229-232

17. Crawford A.N, Lennon M.A. Dental attendance patterns among mothers and their children in an area of social deprivation. Community Dental Health 1992; 9(3): 289-94

18. Sogaard A.J, Aaro L.E, Helx L.A. Irregular users of dental services among Norwegian adults. Acta Odontol Scand 1987; 45: 371-81

19. McGrath C, Yeung C.Y, Bedi R. Are single mothers in Britain failing to monitor their oral health. Postgrad Med J 2002;; 78(918): 229-32

20. Beal J.F. Social factors and preventive dentistry. In: Murray J.J ed. The prevention of dental disease. Oxford: Oxford University Press, 1983; 31342

21. Hayward R.A, Meetz H.K, Shapiro M.F, Freeman H.E. Utilization of dental services: 1986 patterns and trends. J Public Health Dent 1989; $49(3): 147: 52$

22. Chen M.S, Land K.C. Socio economic status (SES) and the health belief model: LISREL analysis of unidimensional versus multidimensional formulations. J. Soc. Bel. Personality 1990; 5: 263-84

23. Syrjala A, Knuutila M, Syrjala E. Reasons preventing regular dental care Community Dent. Oral Epidemiol 1992; 20;10-4

24. Jensen K. Dental care practices and socio economic status in Denmark Community Dent Oral Epidemiol 1974; 2: 273-81

25. National Centre for Health Statistics. United States. 2001. With Urban and Rural Health Chartbook. Hyattsville, MD: National Center for Health Statistics; 2001.

26. Bloom B, Gift H.C, Jack S. S. Dental services and oral health. Vital Health Stat 1992; 63: 1-95

27. Johnsen D.C, Pappas L.R, Cannon D, Goodman S.J. Social factors and diet diaries of caries free and high caries 2 to 7 year olds presenting for dental care in West Virginia. Pediatr Dent 1980; 2: 279-86

28. Silver D.H. A comparison of 3 year olds' caries experience in 1973, 1981 and 1989 in a Hertfordshire town, related to family behaviour and social class. Br. Dent J. 1992; 172: 191-7 
29. Petersen P.E, Juul PoulsenV, Ramahaleo J, Ratsifaritara C. Dental caries and dental health bchaviour situation among 6- and 12-year old urban school children in Madagascar. Afr. Dent. J.1991; 5: 1-7

30. Watson M.R, Gibson G, Guo I. Women's oral health awareness and care seeking characteristics: a pilot study. J Am Dent Assoc 1998;129: 1708-16

31. Kalsbeek H, Truin G.J, Poorterman J.H. Oral Health and Gender. Ned Tijdschr. Tandheelkel 1998; 105: 408-11

32. Petersen P.E, Hadsi R, Ai-Zaabi I.S, Hussein J.M, Behbehani J.M,
Skougaäd M. R, Vigild M.J. Dental Knowledge, attitude and behaviour among Kuwaiti mothers and school teachers. J Pedod 1990;14: 158-64

33. Al-Tamini S, Petersen P.E. Oral health situation of school children, mothers and school teachers in Saudi Arabia. Int Dent $J$ 1998; 48: 180-6

34. Petersen P.E, Esheng Z. Dental caries and oral health behaviour situation of children, mothers and school teachers in wuhan, People's Republic of China. Int Dent J 1998; 48: 210-6

TABLE 3:DENTAL VISITS BY MOTHER'S AGE

\section{Dental visits}

1. Mother's visits.

(i) Yes

(ii) No

2. Child's visit.

(i) Yes

(ii) No

3. Frequency of mothers' visit

(i) Twice a year.

(ii) Once a year.

(iii) When there is a problem.

4. Reasons for non-visitation.

(i) Distance.

2(1.9)

(ii) Fear of dental treatment.

(iii) Never had a dental problem.

$6(100)$

(iv) Traditional healer. -

\section{0-29}

$\mathrm{N}(\%)$

12(10.3)

$105(89.7)$

$6(5.1)$

$6(100)$

$111(94.9)$

$10(83.3)$

$1(9.1)$

30-39

$\mathrm{N}(\%)$

11(17.5)

$52(82.5 \%)$

2(3.2)

$61(96.8)$

13(92.9)
$\mathrm{N}(\%)$

p-

value

2.854

0.415

0.875

0.831

$165(94.3)$

12.374

0.416 